Revue d'histoire de l'Amérique française

Ali REVUE D.HISTOIRE DE L'AMÉRIQUE FRANÇAISE

\title{
Le ministère de la marine dans ses rapports avec Mgr de Pontbriand
}

\section{Roland Lamontagne}

Volume 19, numéro 1, juin 1965

URI : https://id.erudit.org/iderudit/302439ar

DOI : https://doi.org/10.7202/302439ar

Aller au sommaire du numéro

\section{Éditeur(s)}

Institut d'histoire de l'Amérique française

\section{ISSN}

0035-2357 (imprimé)

1492-1383 (numérique)

Découvrir la revue

\section{Citer cet article}

Lamontagne, R. (1965). Le ministère de la marine dans ses rapports avec Mgr de Pontbriand. Revue d'histoire de l'Amérique française, 19(1), 53-55. https://doi.org/10.7202/302439ar d'utilisation que vous pouvez consulter en ligne. 


\section{LE MINISTĖRE DE LA MARINE DANS SES RAPPORTS AVEC MGR DE PONTBRIAND}

Les ministres Maurepas, Rouillé et Machault ont tenu à se ménager la coopération administrative de l'évêque de Québec, Mgr Henri-Marie du Breil de Pontbriand. Tout en maintenant son assistance à l'Église, Maurepas a tendance à prendre le parti des réalités économiques. L'alcool, considéré comme instrument d'échange commercial, par voie de troc, avec les Indiens, provoquait du désordre dans la colonie. La lettre de Maurepas, en date du 27 avril 1742, annonce l'envoi d'une gratification extraordinaire de 3,000 livres et exprime un prudent avertissement, peut-être inspiré par Beauharnois qui profitait personnellement de la traite des fourrures. Elle vise à minimiser l'étendue des abus provoqués par le trafic de l'eau-de-vie.

La traite de l'Eau de Vie aux sauvages est encore un article qui demande un mûr examen avant que de rien faire qui puisse trop la gêner. Il vous aura eté aisé de connoitre combien elle est necessaire non seulement pour le commerce de la Colonie, mais encore pour empecher les sauvages de se livrer aux anglois, et pour les conserver par consequent a la France et a la Religion. Il n'y auroit que les abus qui pourroient se commettre dans cette traitte qu'il faudroit chercher a reprimer; mais j'ay lieu de croire qu'il n'y en a pas de bien considerables. Quoyqu'il en soit si vous jugés absolument necessaire de faire quelque disposition sur cette matiere, le Roy attend de vous que vous y conserverés autant qu'il sera possible les intérêts de l'Etat et de la Colonie.'

Les relations tendues entre le missionnaire Maillart et les Récollets font également l'objet des recommendations du ministre Maurepas, en 1743: "Je me propose donc de prendre les

${ }^{1}$ Archives de l'Archevêché de Québec, F. I-64. 
ordres du Roy, écrit le représentant métropolitain à l'évêque de Québec, pour faire revenir le S. Maillart; et je vais faire chercher un sujet qui puisse être envoyé par le premier vaisseau, et être chargé de la mission des sauvages de l'Isle Royale, où vous sentez bien qu'il ne convient pas d'en entretenir un tel que lui." ${ }^{2}$

Au cours de la guerre de la Succession d'Autriche, des curés se rallient à la cause britannique, dans la région acadienne. La Cour avait appris que " le S. Desenclave, Curé au Port Royal, informoit exactement le Gouverneur Anglois de tout ce qu'il pouvoit apprendre des demarches des françois, et exortoit ses paroissiens a estre fideles au Roy d'Angleterre; que le S. Chevreux, autre curé, prononçoit des excommunications contre ceux de ses paroissiens qui prendroient les armes en faveur des François, et que le S. Miniac, grand vicaire, cachoit mieux ses demarches, mais qu'il agissoit encore plus efficacement pour faire échoüer l'entreprise" 3 militaire de la Nouveile-France. Les considérations que le ministre Maurepas tire de ces événements aboutissent à exclure cette région de la distribution des fonds affectés à l'entretien des curés.

À la veille de la guerre de Sept Ans, le ministre Rouillé informe l'évêque de Québec que les finances métropolitaines sont obérées: "Dans l'état d'épuisement ou se trouvent presentement les finances de $\mathrm{Sa} \mathrm{M}^{\mathrm{a}}$. par les depenses immenses qui ont été faites depuis quelques années en Canada Sa Majesté ne pourroit pas recevoir favorablement une demande de $25 \mathrm{~m} . "$ de fonds extre." 4 Des restrictions de crédit sont temporairement appliquées; elles sont suivies de l'envoi de secours ordinaires par l'entremise de Jean-François Boyer, ancien Evêque de Mirepoix ${ }^{5}$, que le roi, après la mort du Cardinal de Fleury, avait chargé de la distribution des bénéfices. À Versailles, le 15 juin 1755, le ministre Machault d'Arnouville qui avait remplacé Rouillé écrivait à Mgr de Pontbriand: "j'ai obtenu pour vous ... une grati-

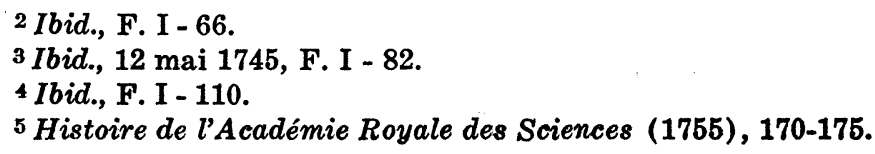


fication extraordinaire de 6,000" sur le Tresor Royal, laquelle pourra être payée au porteur de votre procuration en France". ${ }^{6}$ Machault profitait de cette occasion pour inciter l'évêque de Québec à le mettre au courant de l'administration du Canada. "Vous me ferez plaisir aussi de me communiquer vos observations non seulement sur ce qui peut avoir rapport à la Religion mais même sur les autres parties de l'administration de la Colonie."

Ces lettres des ministres de la Marine ne dépassent pas le cadre d'une correspondance de bon ton sur les problèmes coloniaux. Sous forme de crédits métropolitains, le facteur de contrainte, pour avoir été adouci par l'expression de paroles aimables, n'en demeure pas moins présent. Faute de documents, on ne peut apprécier dans quelle mesure il a joué un rôle sur le plan des relations entre l'Église et l'Etat, au temps de Mgr de Pontbriand.

Université de Montréal.

ROLAND LAMONTAGNE

${ }^{6}$ Archives de l'Archevêché de Québec, F I - 112.

Nous nous excusons auprès de nos collaborateurs du retard que, par force majeure, nous sommes obligés de consentir à la publication de leur articles. Ils peuvent être assurés qu'on leur fera place aussitôt que possible dans nos prochaines livraisons.

N.D.R. 